\title{
Corrigendum
}

\section{Corrigendum to "Sleep-Disordered Breathing in Patients with Heart Failure: New Trends in Therapy"}

\author{
Anna Kazimierczak, Paweł Krzesiński, Krystian Krzyżanowski, and Grzegorz Gielerak \\ Department of Cardiology and Internal Diseases, Military Institute of Medicine, Szaserow Street 128, 04-141 Warsaw, Poland \\ Correspondence should be addressed to Anna Kazimierczak; akazimierczak@wim.mil.pl \\ Received 31 August 2015; Accepted 18 October 2015 \\ Copyright (c) 2015 Anna Kazimierczak et al. This is an open access article distributed under the Creative Commons Attribution \\ License, which permits unrestricted use, distribution, and reproduction in any medium, provided the original work is properly \\ cited.
}

In the paper titled "Sleep-Disordered Breathing in Patients with Heart Failure: New Trends in Therapy" [1], we would like to complete the text of our paper with information about funding body as follows.

\section{Acknowledgment}

The paper is a result of a project funded by the National Center for Science (Project no. N N 402489 840).

\section{References}

[1] A. Kazimierczak, P. Krzesiński, K. Krzyżanowski, and G. Gielerak, "Sleep-disordered breathing in patients with heart failure: new trends in therapy," BioMed Research International, vol. 2013, Article ID 459613, 10 pages, 2013. 


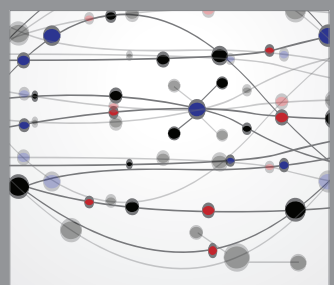

The Scientific World Journal
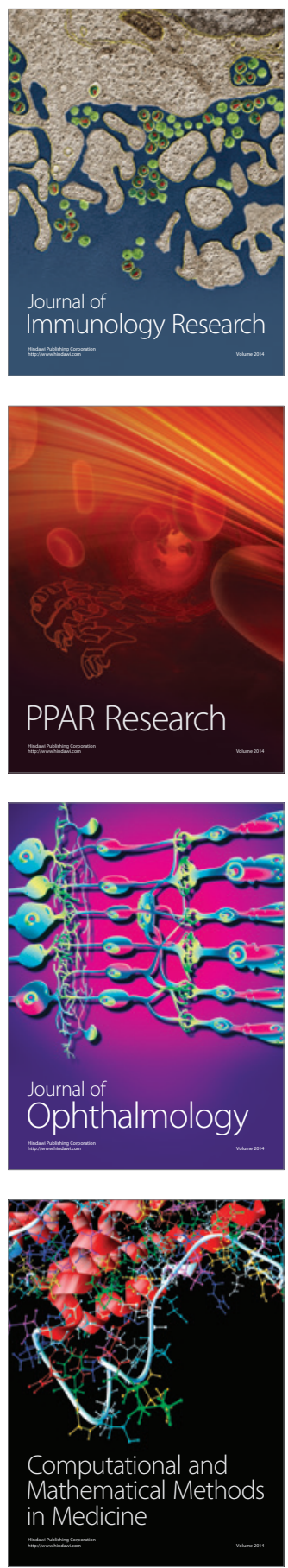

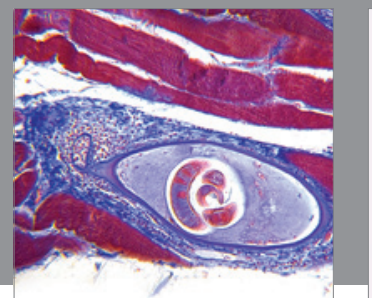

Gastroenterology

Research and Practice
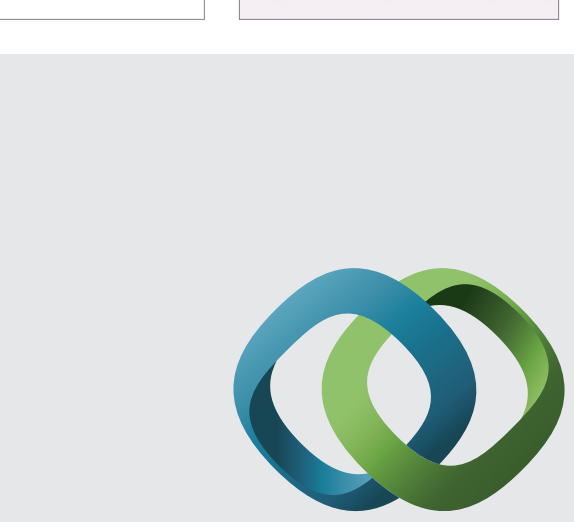

\section{Hindawi}

Submit your manuscripts at

http://www.hindawi.com
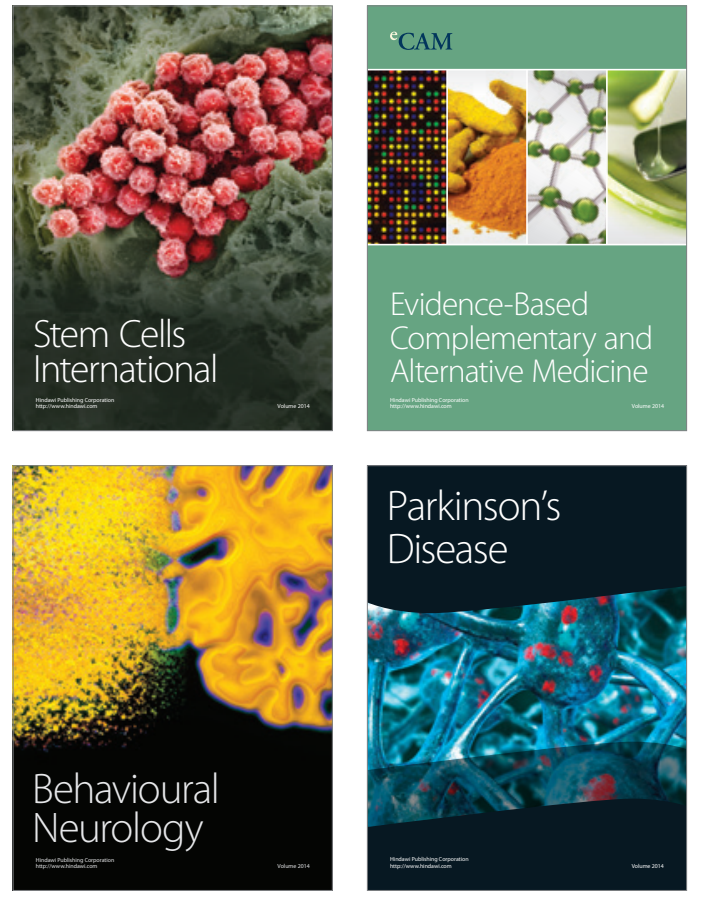
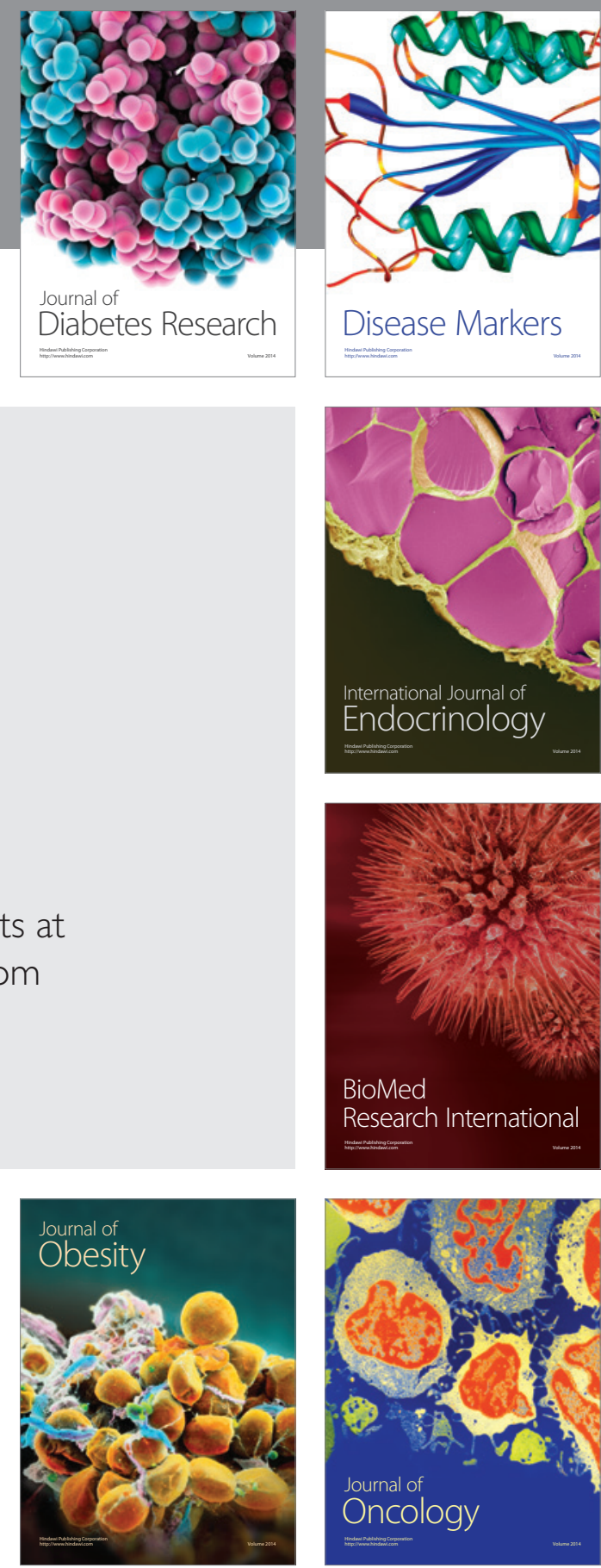

Disease Markers
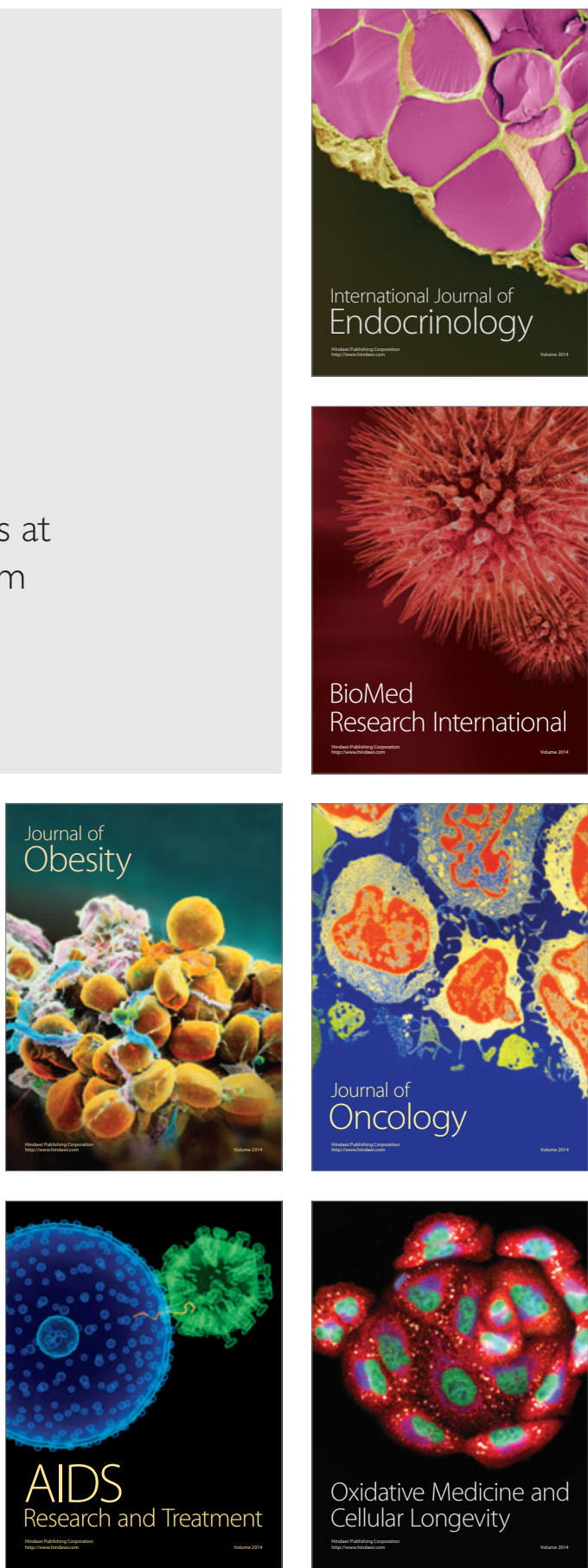